\section{Comparative Analysis of Different Specific Indices of Hand Impairment in Systemic Sclerosis}

\section{To the Editor:}

Hand involvement is often the first clinical manifestation of systemic sclerosis ( $\mathrm{SSc}$ ) during the disease course. Some indices such as finger-to-palm distance in flexion $(\mathrm{FTP})^{1}$, the Hand Anatomic Index $(\mathrm{HAI})^{2}$, and the Hand Mobility in Scleroderma test (HAMIS) ${ }^{3}$ have been developed to assess functional impairment by testing the reduction in range of motion or evaluating inability, but there is still no consensus whether they yield different information or are mutually interchangeable.

We compared these 3 assessment tools used to quantify hand impairment in SSc, considering their associations with organ involvement.

Our analyses were based on 80 consecutive patients with SSc (68 women, 12 men) referred to the Division of Rheumatology, Istituto Gaetano Pini, Milan; 60 were classified as having limited cutaneous disease (lcSSc; mean age $61.3 \mathrm{yrs}$ ) and 20 as having diffuse cutaneous disease (dcSSc; mean age $58.9 \mathrm{yrs}$ ). Judged from the first symptom attributable to SSc, $20(33.3 \%) \mathrm{lcSSc}$ and $6(30 \%) \mathrm{dcSSc}$ patients had disease of recent onset $(<5$ and 3 years, respectively), whereas $40(66.7 \%) 1 c S S c$ and
$14(70 \%)$ dcSSc patients had intermediate/late onset disease ( $\geq 5$ and 3 years $)^{4}$.

To determine patients' disease profiles on the basis of the pattern of organ involvement (lung, esophagus, cardiac, renal, and hand involvement) assessed for the study, we used cluster analysis, a technique that allows patients with clinically similar characteristics to be ordered into different homogeneous groups (or clusters). In general, patients in Group B showed more organs involved and hand impairment than patients in Group A (Table 1) ${ }^{5}$.

As 2 groups were identified, the probability of major organ involvement (Group B) on the basis of hand measures was investigated by logistic regression. The discriminating ability of each model (consisting of a single index or different combinations of the indices) was computed using the area under the receiver-operating characteristic (ROC) curve with a 95\% bootstrap confidence interval and 1000 bootstrap resamples. Moreover, in order to evaluate the discriminating ability of the indices in classifying patients, the best cutoff point for each ROC curve was calculated as the values corresponding to the highest sum of sensitivity and specificity.

Table 2 shows the area under the ROC curve (C-index) for each model, together with its confidence interval, the best cutoff point, and the corre-

Table 1. Overview of the main findings of the cluster analysis based on similarity of the patients' clinical profiles. The frequency distribution of the various characteristics of the clusters are shown. Pulmonary involvement was defined as the presence of bibasilar fibrosis on standard chest radiographs or high-resolution computed tomography scans and/or pulmonary arterial hypertension detected by means of color Doppler echocardiography and confirmed by right-heart catheterization; esophageal involvement as barium radiography hypomotility; cardiac involvement as the presence of pericarditis, arrhythmia, or left ventricular congestive heart failure; renal involvement as malignant hypertension and/or rapidly progressive renal failure; hand involvement was defined as the presence of arthralgia, arthritis, flexion contractures, and/or digital ulcers. Data are percentages.

\begin{tabular}{lccc}
\hline & $\begin{array}{c}\text { Group A: } \\
\text { Minor Extent of Organ } \\
\text { Involvement, N=61 }\end{array}$ & $\begin{array}{c}\text { Cluster B: } \\
\text { Major Extent of Organ } \\
\text { Involvement, N }=19\end{array}$ & $\begin{array}{c}\text { Complete Case } \\
\text { Series, } \\
\text { N = } 80\end{array}$ \\
\hline dcSSc & 8 & 79 & 25 \\
lcSSc & 92 & 21 & 75 \\
Hand involvement & 44 & 63 & 49 \\
$\quad$ Arthralgias & 10 & 11 & 10 \\
Arthritis & 41 & 63 & 46 \\
Digital ulcers & 13 & 74 & 28 \\
$\quad$ Flexion contractures & 10 & 79 & 49 \\
Heart involvement & & & 23 \\
Lung involvement & 34 & 95 & 69 \\
$\quad$ Bibasilar fibrosis & 10 & 63 & \\
Pulmonary arterial hypertension & 62 & 89 & \\
Esophagus involvement & & & \\
\hline
\end{tabular}

dcSSc: diffuse cutaneous systemic sclerosis; lcSSc: limited cutaneous systemic sclerosis.

Table 2. Discriminating capacity of the hand function indices in relation to the 2 patient groups with minor and major extent of organ involvement.

\begin{tabular}{|c|c|c|c|c|}
\hline Model & $\begin{array}{l}\text { C-Index } \\
(95 \% \text { CI })\end{array}$ & $\begin{array}{c}\text { Best Cutoff for } \\
\text { Classifying Major Extent } \\
\text { of Organ Involvement }\end{array}$ & Sensitivity & Specificity \\
\hline HAI & $0.80(0.66-0.91)$ & $\leq 2.6$ & 79 & 79 \\
\hline HAMIS & $0.81(0.69-0.91)$ & $\geq 4.5$ & 63 & 89 \\
\hline FTP & $0.73(0.60-0.87)$ & $\geq 1.5$ & 58 & 82 \\
\hline $\mathrm{HAI}+\mathrm{FTP}$ & $0.84(0.73-0.93)$ & $\mathrm{HAI} \leq 2.5, \mathrm{FTP} \geq 1$ & 74 & 80 \\
\hline FTP + HAMIS & $0.82(0.71-0.92)$ & HAMIS $\geq 2.5$, FTP $\geq 1$ & 79 & 71 \\
\hline HAI + HAMIS & $0.83(0.72-0.94)$ & $\mathrm{HAI} \leq 2.5, \mathrm{HAMIS} \geq 2.5$ & 79 & 85 \\
\hline HAI + HAMIS + FTP & $0.85(0.74-0.95)$ & $\mathrm{HAMIS} \geq 4.5, \mathrm{HAI} \leq 2.6, \mathrm{FTP} \geq 0.5$ & 84 & 79 \\
\hline
\end{tabular}

HAI: Hand Anatomic Index; HAMIS: Hand Mobility in Scleroderma; FTP: finger-to-palm distance. 
sponding sensitivity and specificity. HAMIS and HAI showed good discriminating ability, although if the confidence intervals are taken into account, the results of all the models were similar and suggest that the combined use of 2 or 3 indices does not increase their discriminating capacity with respect to organ involvement. Overall, the results suggest an interesting association between severity of hand involvement and severity of organ involvement.

In terms of the putative best cutoff points to discriminate patients with major extent of organ involvement, HAMIS was the most specific (89\%); HAI showed good sensitivity and specificity. The combined use of the 3 indices led to greater sensitivity, suggesting that patients could be excluded from the group with major extent of organ involvement if HAMIS is < 4.5, $\mathrm{HAI}>2.6$, and FTP $>0.5$. The suggested cutoff points obtained on the basis of the ROC curves are only intended to illustrate potential severity criteria and are not for use in clinical practice.

As the 3 indices showed comparable capacity to discriminate both alone and together, their use in clinical practice may be based on practical considerations, i.e., ease of administration and scoring, training, and completeness.

The HAI measures hand deformity, which in SSc patients is due to flexural contractures and joint immobility ${ }^{2,6}$. Although the HAI has been validated in SSc, its use in clinical practice may be limited by the fact that it requires some training and no clear cutoff point has yet been established. Moreover, Roberts-Thomson, et $a l^{7}$ have recently proposed a modified version (mHAI) derived from an equation that seems to require further measurement skills, and may therefore be less suitable for practical, rapid, and standardized hand impairment assessments.

Our findings also showed that the HAMIS score correlates with SSc with extent of major organ involvement. HAMIS is a performance-based test that explores wrist and finger motion. As it includes items covering the most frequent and specific impairments seen in SSc, it is useful for monitoring specific occupational and physical therapy programs 8 .

Finally, FTP is widely used ${ }^{1,9}$ because it is an easy, rapid, and valid means of discriminating the severity of joint involvement, although it is less discriminating than the HAI or HAMIS. This may be explained by the fact that some SSc patients with more severe contractures have small FTP measurements because their fingers are fixed in severe flexion and cannot be extended; this obviously causes marked hand dysfunction but increases the number of falsely normal FTP results. An alternative "delta FTP" has recently been proposed that measures the total excursion of the third fingertip, defined as the FTP distance in full extension minus this distance in full flexion, thus overcoming the limitations of the traditional FTP ${ }^{10}$.

Although HAI and FTP show the best discriminating ability, a combination of HAMIS and FTP (or delta FTP) may be the most practical means of assessing hand impairment in patients with SSc. Our findings agree with the hypothesis that the seriousness of hand involvement reflects the extent of organ involvement.
FRANCESCA INGEGNOLI, MD, Division of Rheumatology, Istituto Gaetano Pini and Department of Internal Medicine, Istituto Auxologico IRCCS; PATRIZIA BORACCHI, PhD; FEDERICO AMBROGI, PhD, Institute of Medical Statistics and Biometry; PIER LUIGI MERONI, MD, Division of Rheumatology, Istituto Gaetano Pini and Department of Internal Medicine, Istituto Auxologico IRCCS, University of Milano, Piazza Cardinal Ferrari 1, 20122 Milano, Italy. Address correspondence to Dr. Ingegnoli; E-mail: francesca.ingegnoli@unimi.it

\section{REFERENCES}

1. Medsger TA Jr, Silman AJ, Steen VD, Black CM, Akesson A, Bacon PA, et al. A disease severity scale for systemic sclerosis: development and testing. J Rheumatol 1999;26:2159-67.

2. Roberts-Thomson AJ, Massy-Westropp N, Smith MD, Ahern MJ, Highton J, Roberts-Thomson PJ. The use of the Hand Anatomic Index to assess deformity and impaired function in systemic sclerosis. Rheumatol Int 2006;26:439-44.

3. Sandqvist G, Eklund M. Hand Mobility in Scleroderma (HAMIS) test: the reliability of a novel hand function test. Arthritis Care Res 2000;13:369-74.

4. Medsger TA Jr, Steen VD. Classification, prognosis. In: Clements PJ, Furst DE, editors. Systemic sclerosis. 1st ed. Philadelphia: Lippincott Williams \& Wilkins; 1996:51-79.

5. Ingegnoli F, Boracchi P, Ambrogi F, Gualtierotti R, Galbiati V, Meroni PL. Hand impairment in systemic sclerosis: Association of different hand indices with organ involvement. Scand J Rheumatol 2010 May 17. Epub ahead of print

6. Roberts-Thomson AJ, Roberts-Thomson PJ. Quantitative and qualitative assessment of hand function and deformity in systemic sclerosis. Rheumatol Int 2007;27:509-10.

7. Roberts-Thomson AJ, Englert H, Ahern MJ, Smith MD, Highton J, Roberts-Thomson PJ. A modified hand anatomic index to assesss hand deformity in scleroderma. Rheumatol Int 2009;29:847-8.

8. Sandqvist G, Hesselstrand R, Eberhardt K. A longitudinal follow-up of hand involvement and activities of daily living in early systemic sclerosis. Scand J Rheumatol 2009;38:304-10.

9. Medsger TA Jr, Bombardieri S, Czirjak L, Scorza R, Della RA, Bencivelli W. Assessment of disease severity and prognosis. Clin Exp Rheumatol 2003;21 Suppl:S42-S46.

10. Torok KS, Lucas M, Domsic RT, Medsger TA Jr. An alternative method of measuring finger joint contracture in systemic sclerosis [abstract]. Arthritis Rheum 2008;58 Suppl:S827.

J Rheumatol 2010;37:10; doi:10.3899/jrheum.100260 